\title{
A RELIGIOSIDADE/ESPIRITUALIDADE NA PRÁTICA DO CUIDADO ENTRE PROFISSIONAIS DA SAÚDE
}

\author{
Religiosity/SPIRItuality in CARE PRACtice Among health PROFESSIONALS
}

\author{
LucAs GUILHERME TezTLAfF DE GeRONE(*)
}

\begin{abstract}
RESUMO
Contexto: A investigação científica sobre espiritualidade, religiosidade e saúde tem adquirido espaço nas rodas de debates e nas pesquisas acadêmicas ${ }^{1}$. Contudo, pouco se trata da espiritualidade/religiosidade em uma perspectiva teológica que contribua para o contexto do cuidado em saúde. Objetivo: O presente estudo apresenta uma revisão de literatura sobre espiritualidade, religiosidade e saúde. Especificamente, busca evidenciar as metodologias destas literaturas no intento de apontar o papel da teologia na prática do cuidado entre profissionais da saúde. Métodos: Pesquisa de dissertações de mestrado, teses de doutorado e periódicos sobre espiritualidade, religiosidade e saúde nas bases de dados da CAPES e SCIELO. Resultados: encontraram-se 348 dissertações de mestrado e teses de doutorado e 62 periódicos sobre espiritualidade, religiosidade e saúde. Dentre as 348 dissertações e teses, apenas 2,58\% (9) são da área da teologia. Das 410 (dissertações, teses e artigos) utilizou-se 29 para a discussão do tema, sendo desses apenas 2 os estudos da teologia. Considerações: $O$ tema é amplo, e por isso, faz-se necessária a continuidade de novas pesquisas interacadêmicas sobre a temática em questão. Considera-se a importância de mais estudos da teologia, haja vista sua significativa contribuição para a humanização na saúde e no cuidado integral.
\end{abstract}

Palavras-Chave: Cuidado. Espiritualidade. Saúde. Profissional de saúde. Pastoralista.

\begin{abstract}
Context: scientific research on spirituality, religion and health has purchased space on rounds of debate and academic research. However, just very little about spirituality, religiosity in a theological perspective that contributes to the health care context have been written. Objective: this study presents a literature review on spirituality, religiosity and health, specifically highlighting the methodological of these literatures in an attempt to point out the role of theology in care practices among health professionals. Methods: research master's dissertations, doctoral theses and journals on spirituality, religiosity and health in CAPES and SCIELO databases. Results: we found 348 master's dissertations and doctoral theses and 62 periodicals on spirituality, religiosity and health. Among 348 dissertations and theses, only $2.58 \%$ (9) are from the area of theology. Between 410 (dissertations, theses and articles), 29 were used for the discussion of the topic, and only two studies of theology. Consideration/conclusion: the theme is broad, and therefore it is necessary to continue academic new researches on the topic in question. Thus, we consider the importance of further study of theology, as its significant contribution to the humanization in the health and comprehensive care.
\end{abstract}

KEYWORDS: Care. Spirituality. Health. Health Professional. Pastoralist.

(*) Bacharel em Teologia. Mestre em Teologia pela Pontifícia Universidade Católica do Paraná. Professor de teologia. Presidente do Instituto de Bem Estar Social de Presidente Prudente - SP, que visa ações no campo da saúde. Membro da diretoria do Instituto Cristão de Desenvolvimento. E-mail: lucasgerone@gmail.com.

1 Esse estudo é parte de uma pesquisa mais ampla realizada para o Mestrado em Teologia, da PUC PARANÁ. Para dissertação completa, ver GERONE, 2015. 


\section{INTRODUÇÃO}

Durante toda a história da humanidade, os temas religiosidade/espiritualidade e saúde estiveram interligados, influenciando diretamente o trabalho dos profissionais da saúde. Por isso, para Moreira-Almeida (2010, p. 18), "religiosidade e espiritualidade têm sido objeto de um crescente interesse entre clínicos e pesquisadores na área de saúde". Nos últimos anos, as pesquisas no campo da saúde têm constatado que a religião é um fator psicológico e social poderoso, que influencia grandemente a saúde das pessoas (KOENIG, 2012, p. 38).

No decorrer deste estudo nota-se que dentro dos campos da saúde, como a enfermagem, a psicologia e outros, buscam-se entender a relação entre as práticas e experiências religiosas e espirituais (as orações, os louvores e as meditações), no contexto do cuidado em saúde. Diante disso, tem-se como objetivos deste estudo apontar como os profissionais da saúde enxergam a religiosidade, espiritualidade e saúde, e identificar possíveis lacunas e oportunidades para a teologia no que tange à prática de cuidado entre os profissionais da saúde. Para alcançar tais objetivos, este estudo estrutura-se da seguinte forma: as definições das terminologias, o método utilizado no levantamento dos estudos, os resultados, discussões e, por fim, algumas considerações sob a ótica teológica.

\section{DEFINIÇÕES DAS TERMINOLOGIAS: RELIGIOSIDADE, ESPIRITUALIDADE E SAÚDE}

Não se pretende emitir aqui uma noção completa e final sobre religiosidade, espiritualidade e saúde, mas busca-se construir um panorama dos termos dentro de uma percepção teológica e da área saúde.

De um lado, a religiosidade é uma qualidade daquilo que faz parte da religião, aqui entendida a partir de sua etimologia latina, religare, que significa "religação" entre o homem e Deus (DERRIDA, 2000, p. 52). De acordo com Koenig (2012, p. 11), religião é um sistema de crenças e práticas observado por um grupo de pessoas que se apoiam em rituais ou em um conjunto de escrituras e ensinamentos "que reconhecem, idolatram, comunicam-se com ou se aproximam do Sagrado, do Divino, de Deus". Por outro lado, a espiritualidade é uma dimensão existencial dinâmica, cultivada no espírito, que impulsiona o ser humano consciente em seus conhecimentos e escolhas vitais, e que pode (ou não) estar relacionada à religião (SOUZA, 2013, p. 97). 
Para Puchalski (2006, p. 14-15), médica e uma das pioneiras no movimento para integrar a espiritualidade nos cuidados de saúde, espiritualidade é a:

busca inerente de cada pessoa do significado e do propósito definitivo da vida. Esse significado pode ser encontrado na religião, mas, muitas vezes pode ser mais amplo do que isso, incluindo a relação com uma figura divina ou com a transcendência, relações com os outros, bem como a espiritualidade encontrada na natureza, na arte e no pensamento racional. Todos esses fatores podem influenciar o modo como os pacientes e os profissionais da saúde percebem a saúde e a doença e como interagem uns com os outros.

Os fatores que permeiam a noção de espiritualidade - como sentido e propósito de vida, dentre outros - influenciam as percepções sobre a noção de saúde dos pacientes e dos profissionais da saúde, porque estes fatores de espiritualidade se tornam um indicador positivo para a saúde, como por exemplo, a Fé, que resulta em esperança, e assim pode ajudar o desenvolvimento do tratamento médico. Nesse contexto, espiritualidade pode ser um dos indicadores da noção de saúde.

A noção de saúde mais utilizada no meio acadêmico é a da própria OMS, como sendo uma situação de completo bem-estar físico, mental e social. Para Scliar, essa noção busca expressar "uma vida plena” (2007, p. 37). Por isso, Luz (2013) afirma que se acrescentou a dimensão espiritual à noção de saúde, visto que a religiosidade/espiritualidade influencia toda a vida - os valores, os comportamentos, a política, a economia, a cultura, a educação -, os quais se refletem diretamente na noção de saúde.

\section{MÉTODO UTILIZADO NO LEVANTAMENTO DOS ESTUDOS}

As palavras de busca para pesquisa nos bancos de dados foram religiosidade, espiritualidade e saúde. Foram utilizados dois bancos de dados: o de teses e dissertações da Coordenação de Aperfeiçoamento de Pessoal de Nível Superior (CAPES) e os artigos indexados pela Scientific Electronic Library Online (SCIELO), biblioteca eletrônica que abrange uma coleção selecionada de periódicos científicos brasileiros.

No banco de teses e dissertações da CAPES, o levantamento ficou, em um primeiro momento, entre o período de 1987 (data inicial disponível para consulta) a 20 de agosto de 2013. Nesse período foram encontradas 296 dissertações de mestrado e 81 teses de doutorado. Desses estudos, 29 foram descartados por não se relacionarem diretamente ao tema, obtendo-se, portanto, 348 estudos. Em um segundo momento, no dia 14 de janeiro de 2015, 
foi feita uma nova busca com as palavras religiosidade, espiritualidade e saúde, e não foram encontrados estudos posteriores a 2012, o que significa não haver nenhuma dissertação de mestrado ou tese de doutorado em 2013 e 2014. Notouse, nesse segundo momento, que a ferramenta de busca de teses da CAPES está mais aprimorada, com uma melhor visualização dos estudos e possibilidades de encontrar informações mais rapidamente, tais como: o autor, a área do conhecimento, instituição de ensino e data da defesa. Todavia, foi encontrado um total de 47 estudos, já visualizados na primeira busca. Ressalta-se a discrepância entre a quantidade de estudos encontrados na primeira e na segunda busca.

A busca na SCIELO se restringiu ao período entre 2000 (data inicial disponível para consulta) e 24 de agosto de 2013 (data final da revisão). Foram encontrados 59 artigos científicos produzidos no Brasil. Em novo momento, no dia 03 de novembro de 2015, foi feita uma nova busca com as palavras religiosidade, espiritualidade e saúde, o que resultou num total de 40 estudos, ou seja, nessa busca houve uma diminuição dos estudos disponíveis no banco de dados $^{2}$. Entre os 40 estudos, 37 já foram visualizados na primeira busca e apenas 3 estudos são novos. Diante dos resultados discrepantes entre a primeira e segunda busca, preferiu-se somar os 59 artigos da primeira busca com os 3 artigos encontrados na segunda busca, obtendo-se, portanto, 62 artigos indexados na SCIELO - perfazendo, assim, entre os 62 artigos da SCIELO e os 348 estudos da CAPES, um total de 410 estudos sobre religiosidade, espiritualidade e saúde (RES).

O exame dos 410 estudos mostra os seguintes resultados: (a) 130 trabalhos fazem referência aos termos religiosidade/espiritualidade e saúde como achados em estudos diversos, tais como religiosidade/espiritualidade e qualidade de vida, religiosidade/espiritualidade no processo de reabilitação de uso de drogas ou entorpecentes, e outros; (b) 125 trabalhos abordam diretamente o tema da religiosidade/espiritualidade e saúde, tais como coping religioso/espiritual (CRE) em situações de dor, sofrimento e estresse, e espiritualidade e religiosidade e a cura de doenças; (c) em 126 trabalhos a religiosidade/espiritualidade aparece como um achado em diversos temas ligados aos profissionais da saúde, como, por exemplo, bioética, tecnologia, humanização, qualidade de vida dos pacientes e outros; (d) 29 estudos foram selecionados por

${ }^{2}$ Não se encontrou nos sites da CAPES e da SCIELO informações sobre a diminuição dos estudos ou mudanças sobre os resultados de busca dos estudos. 
abordarem diretamente a questão da religiosidade/espiritualidade na prática do cuidado entre os profissionais da saúde:

TABELA 1 - Estudos acadêmicos

\begin{tabular}{|l|l|l|}
\hline $\begin{array}{l}\text { Enquadramento } \\
\text { acadêmico do estudo }\end{array}$ & $\begin{array}{l}\text { Banco de dados de } \\
\text { onde foi retirado o } \\
\text { estudo }\end{array}$ & $\begin{array}{l}\text { Quantidade de } \\
\text { estudos } \\
\text { encontrados }\end{array}$ \\
\hline Dissertações de mestrado & CAPES & $17(61 \%)$ \\
\hline Teses de doutorado & CAPES & $5(18 \%)$ \\
\hline Artigos & SCIELO & $7(26 \%)$ \\
\hline TOTAL & & $\mathbf{2 9}$ \\
\hline
\end{tabular}

Sobre as temáticas abordadas nestes 29 estudos, encontra-se a religiosidade/espiritualidade no campo da saúde, no cuidado ou na assistência prestada por profissionais da saúde e pastoralistas/capelães, no contexto hospitalar e na vida pessoal dos profissionais, e na formação acadêmica e no trabalho dos profissionais da saúde. Os 29 estudos selecionados serão abordados na discussão e considerações.

\section{RESULTADOS}

Apontam-se os resultados acerca das 17 dissertações de mestrado e das 5 teses de doutorado, ou seja, dos 22 estudos da CAPES, que representam $76 \%$ dos 29 estudos selecionados. Também, descrevem-se programas e obras importantes na área de pesquisa sobre religiosidade, espiritualidade e saúde. Sobre isso, há que se fazerem alguns adendos no levantamento apresentado:

1) A Revista Estudos da Religião - REVER é a única dentre os Programas de Teologia e Ciências da Religião indexada no SCIELO. Em razão do levantamento dos artigos ter priorizado o Banco de Dados da SCIELO, as Revistas da área de Teologia e Ciências da Religião ficaram excluídas. Todavia, destaca-se que a REVER dispõe de notórios levantamentos do estado de pesquisas sobre espiritualidade e saúde, como por exemplo, de Martha Henning e Carmen Moré (2009), que descrevem 27 publicações sobre Psicologia e Religião; desses, 5 são sobre a influência da religiosidade em processos clínico-terapêuticos.

2) Parece-nos de bom tom, destacar que na área da Teologia e Ciências da Religião há dois programas onde aparecem pesquisas (e produções 
não indexadas na SCIELO) relacionando espiritualidade e saúde: o de Ciências da Religião, da Universidade Federal de João Pessoa e o Programa de Teologia da PUC-PR (PEREIRA \& KLÜPPEL, 2014; ESPERANDIO, 2013; ESPERANDIO, 2014a; ESPERANDIO, 2014b; SIMOES et al, 2012; COURAS \& KLÜPPEL, 2009; KLÜPPEL \& SOUSA, 2009; KLÜPPEL et al, 2007).

3) Salienta-se a importância da obra de Paiva (2007). O autor é uma influência entre as pesquisas sobre a teoria do coping religioso no Brasil. Paiva, através do Grupo de Pesquisa Psicologia e Senso Religioso da ANPEPP3 realizou um simpósio marcante com a ilustre presença de K. Pargament 4 . Sua escala (RCOPE) sobre o coping religioso foi traduzida, verificada e aplicada com êxito por pesquisadores brasileiros, conforme disposto por Panzini (2004).

Sobre as áreas do conhecimento dos 22 estudos da CAPES, encontram-se:

TABELA 2 - Áreas do conhecimento

\begin{tabular}{|l|l|}
\hline $\begin{array}{l}\text { Área do } \\
\text { conhecimento }\end{array}$ & $\begin{array}{l}\text { Quantidade de } \\
\text { estudos }\end{array}$ \\
\hline Administração & $1(4,54 \%)$ \\
\hline Antropologia & $2(9,09 \%)$ \\
\hline Bioética & $2(9,09 \%)$ \\
\hline Saúde coletiva & $2(9,09 \%)$ \\
\hline Teologia & $2(9,09 \%)$ \\
\hline Psicologia & $4(18,18 \%)$ \\
\hline Ciências da religião & $4(18,18 \%)$ \\
\hline Enfermagem & $5(\mathbf{2 2 , 7 2 \% )}$ \\
\hline Total & $\mathbf{2 2 ( 1 0 0 \% )}$ \\
\hline
\end{tabular}

Sobre as instituições de ensino dos 22 estudos, encontram-se:

3 Associação Nacional de Pesquisa e Pós-graduação em Psicologia . Site: <http://site.anpepp.org.br/>.

4 Professor de Psicologia Cliníca na Bowling Green State University. Publicou mais de 250 artigos sobre religião e saúde mental. Editor-chefe dos dois volumes do APA Handbook of Psychology, Religion and Spirituality. Site: <http://www.cbpabp.org.br/hotsite/kenneth-i-pargament/>. 
TABELA 3 - Instituições de ensino

\begin{tabular}{|l|l|}
\hline Instituições & $\begin{array}{l}\text { Quantidade de } \\
\text { estudos }\end{array}$ \\
\hline Universidade Católica de Pernambuco & $1(4,54 \%)$ \\
\hline Universidade Federal do Ceará & $1(4,54 \%)$ \\
\hline Universidade Federal do Rio de Janeiro & $1(4,54 \%)$ \\
\hline Universidade de Brasília & $1(4,54 \%)$ \\
\hline Centro Universitário São Camilo & $2(9,09 \%)$ \\
\hline Escola Superior de Teologia & $2(9,09 \%)$ \\
\hline Pontifícia Universidade Católica de São Paulo & $2(9,09 \%)$ \\
\hline Universidade do Vale do Rio dos Sinos & $2(9,09 \%)$ \\
\hline Universidade Federal da Paraíba & $2(9,09 \%)$ \\
\hline Universidade Federal do Paraná & $2(9,09 \%)$ \\
\hline Universidade Metodista de São Paulo & $2(9,09 \%)$ \\
\hline Universidade de São Paulo/Ribeirão Preto & $4(18,18 \%)$ \\
\hline Total & $\mathbf{2 2 ( 1 0 0 \% )}$ \\
\hline
\end{tabular}

Diante do acima exposto, dentre as 22 instituições de pós-graduação da CAPES, 5 (23\%) delas possuem uma tradição cristã e cursos no campo da saúde e teologia. Estas cinco instituições são responsáveis por 9 (41\%) dos estudos entre os 22. São elas: a Universidade Católica de Pernambuco, com um estudo na área da Psicologia; a Escola Superior de Teologia, com dois estudos de Teologia, sendo os únicos entre os 22; a Pontifícia Universidade Católica de São Paulo, com dois estudos, um na área de Ciência da Religião e outro na de Antropologia; a Universidade Metodista de São Paulo, com dois estudos na área da Ciência da Religião; e o Centro Universitário São Camilo, com dois estudos na área da Bioética.

Entre as instituições de ensino dos 22 estudos, destaca-se a Universidade de São Paulo (Ribeirão Preto) como a instituição que mais pesquisou sobre religiosidade/espiritualidade e saúde e profissionais da saúde, com quatro 
estudos ligados ao campo da saúde: um estudo de Psicologia, um estudo de Saúde Coletiva e dois estudos de Enfermagem.

Em relação à produção anual das áreas do conhecimento dos 22 estudos, sobre o período de 1987 a 2012, a Teologia aparenta ter pouquíssima expressividade, com apenas uma produção em 2003 e outra em 2010. Já o campo da saúde produziu em 2003, 2006, 2008 um estudo por ano, sendo um na Psicologia, um na Saúde Coletiva e um na Enfermagem. Em 2009, dois estudos, ambos da Enfermagem; 2010 dois estudos, um da Psicologia e outro da Enfermagem; em 2011 um estudo da Enfermagem; e em 2012 três estudos, dois da Psicologia e um da Enfermagem.

Acerca da produção anual e sobre a discussão dos 7 artigos indexados na SCIELO, que representam 24\% dos 29 estudos selecionados, entre o período de 2000 a 2014, nenhum artigo traz uma discussão teológica. Os 7 artigos possuem discussões no campo da saúde, tendo a Enfermagem três estudo, produzidos em 2002, 2011 e 2013 (um estudo por ano). A Psicologia traz dois estudos, produzidos em 2006 e 2007 (um estudo por ano) e, por fim, dentro da discussão sobre religiosidade, saúde social, religiosidade e os profissionais de saúde, encontram-se dois estudos, produzidos em 2009 e 2010.

\section{DISCUSSÃO}

Os 29 estudos da CAPES e da SCIELO que foram selecionados por abordarem diretamente a questão da religiosidade/espiritualidade na prática do cuidado entre profissionais da saúde foram classificados em quatro categorias.

A primeira categoria relaciona três estudos do campo da oncologia com religiosidade/espiritualidade. A segunda categoria possui oito estudos que discutem religiosidade/espiritualidade na prática do cuidado ou na assistência prestada por profissionais da saúde e pastoralistas/capelães. A terceira categoria possui nove estudos sobre religiosidade/espiritualidade dos profissionais da saúde no contexto hospitalar e na vida pessoal. E a quarta categoria possui oito estudos sobre a integração da religiosidade/espiritualidade na formação acadêmica e no trabalho dos profissionais da saúde.

\section{A ONCOLOGIA E A RELIGIOSIDADE/ESPIRITUALIDADE}

O câncer é uma doença que causa impactos biopsicossociais e espirituais que se refletem no contexto de saúde, no tratamento e no cuidado hospitalar prestado pelos profissionais da área de oncologia. Nesse contexto, para Freitas 
(2012), os profissionais da saúde da área da oncologia percebem que a espiritualidade é um recurso positivo para o enfrentamento do câncer. De fato, em uma pesquisa com seis enfermeiros da área da oncologia, Freitas constatou que estes profissionais acreditam que a espiritualidade é uma dimensão que mobiliza o ser humano para transpor e transcender o seu físico, para enfrentar situações difíceis provocadas pelo câncer.

Em um estudo com psicólogos e médicos sobre a fé como fator de resiliência no tratamento do câncer, Barolomei (2008) constatou que para os profissionais da saúde, a fé presente na religiosidade/espiritualidade é algo útil para o amparo e o fortalecimento no lidar com a problemática da doença.

Em um estudo com enfermeiros, psicólogos, capelães/pastoralistas e médicos inseridos no tratamento do paciente idoso com câncer, Teixeira (2003) constatou que os profissionais da saúde dão importância à fé religiosa enquanto recurso de enfrentamento dos desafios da vida que a doença causa.

\section{A RELIGIOSIDADE/ESPIRITUALIDADE NA PRÁTICA DO CUIDADO PRESTADO POR PROFISSIONAIS DA SAÚDE E PASTORALISTAS/CAPELÃES}

Não há contradições, diante da ausência de saúde, em o paciente recorrer à sua religiosidade/espiritualidade. Para Peres (2007) e Lima (2012), a maior parte dos profissionais da saúde reconhece a importância e valoriza a religiosidade/espiritualidade no cuidado hospitalar.

Para Alves (2011), os médicos, enfermeiros, psicólogos e outros profissionais possuem uma postura incerta diante da questão religiosidade/espiritualidade. De um lado, esses profissionais acreditam ser importante integrar a religiosidade/espiritualidade no cuidado hospitalar devido à sua influência na saúde. De outro, há restrições desses profissionais em relação à religiosidade/espiritualidade quando atrapalham o cuidado hospitalar - por exemplo, aversão de alguns pacientes religiosos a determinadas vacinas ou tratamentos. De acordo com Alves, esta postura incerta dos profissionais está relacionada com a falta de treinamento e de preparo para lidar com a religiosidade/espiritualidade no contexto do cuidado.

Para Bonfim (2010), Marcos Silva (2007) e Alexsandro Silva (2010), a religiosidade/espiritualidade dentro do contexto de cuidado está a cargo de profissionais capelães/pastoralistas, que precisam estar devidamente treinados e preparados para atender a necessidades espirituais.

Entre as funções do capelão/pastoralista inclui-se a de resgatar a dimensão humana por meio da religiosidade/espiritualidade e ser um auxiliador diante do 
sofrimento, ao transmitir uma presença solidária por meio do amor, do consolo e da esperança existentes em Deus ou no elemento transcendente. Para Heimann (2003), o cuidado espiritual prestado por capelães/pastoralistas abarca não somente os pacientes e seus familiares, mas também os profissionais da saúde. Um dos maiores desafios desses profissionais é preservar a vida. Porém, mesmo lidando com certa frequência com questões difíceis, comunicar um prognóstico negativo ao paciente ou óbito aos familiares colocam esses profissionais diante de tarefas difíceis. Em muitas dessas experiências há um sentimento de fracasso por não ter preservado a vida, ou de espelho e projeção - imagem de si próprio na mesma situação. Por isso, Heimann afirma que os profissionais da saúde que assistem pacientes graves no limiar da morte ou em situação de sofrimento precisam, também, ter um acompanhamento espiritual/religioso dentro dos moldes da Psicologia Pastoral5.

Michell Araújo (2011) aponta um modelo de cuidado espiritual que serve como um suporte para os profissionais da saúde que vivenciam o sofrimento e a iminência de morte. Este cuidado espiritual se consolida em três etapas: khronos - fase de construção que se refere ao tempo humano que pode ser contado ou medido; compreende desde a fase de pré-interação até a de orientação do profissional para o paciente; kairós - fase de busca do tempo oportuno, não contado ou medido, e de sentido de vida para o paciente, pautada no amor, na esperança e na fé; e aión - fase da integração que representa o tempo cíclico, de voltar a reviver e aproveitar o tempo vivido ou a vida. Nesta etapa se reafirmam as outras etapas, integram-se os familiares no cuidado e se busca uma integração religiosa, caso o paciente demonstre esse interesse.

\section{A RELIGIOSIDADE/ESPIRITUALIDADE NO CONTEXTO HOSPITALAR E NA VIDA} PESSOAL DOS PROFISSIONAIS DA SAÚDE

Há diversos estudos sobre profissionais religiosos. Eveline Araújo (2007) trabalha com o tema em um hospital espírita, estudando a atuação de médicosespíritas que creem na dimensão espiritual da causalidade das doenças como parte do tratamento. Rezende (2012) estuda a visão da saúde e a prática profissional de médicos e psicólogos espíritas atuantes na Associação MédicoEspírita de Minas Gerais (AMEMG), que realiza uma arte médica híbrida, em que atuam as terapias da medicina ortodoxa/convencional e da medicina paralela, esta última fundamentada no espiritismo, que apresenta a lei de

5 Psicologia Pastoral é a junção do aconselhamento da Psicologia com a Teologia Pastoral na assistência espiritual (HEIMANN, 2003, p. 111). 
ação/reação como orientação, atribuindo ao indivíduo a responsabilidade por seus problemas, sofrimentos e doenças.

Sobre a religiosidade/espiritualidade dos profissionais da saúde, Gobatto (2012) estudou 85 profissionais da saúde, divididos em assistentes sociais, biólogos, enfermeiros, fisioterapeutas, fonoaudiólogos, médicos, nutricionistas, odontologistas, psicólogos e psico-oncologistas. Por meio de uma escala breve de enfrentamento religioso, identificou que a metade dos profissionais (43) não pratica atividades religiosas, mas possuem um grau elevado de espiritualidade. Espíndula (2009), em pesquisa qualitativo-descritiva no Hospital Beneficência Portuguesa, em Ribeirão Preto (São Paulo), buscou identificar o significado da religiosidade para 11 profissionais da saúde: médicos, psicólogos, enfermeiros, dentistas e radioterapeutas. Constatou que sete profissionais não frequentam nenhuma igreja e dizem ser espiritualistas, experimentando uma "religião pessoal", sem influência de um líder religioso ou de uma religião institucionalizada. Também verificou que um profissional acredita que a religião é essencial a todo ser humano. Dois profissionais acreditam que existe proteção divina para suas práticas profissionais e pedem cotidianamente ajuda de Deus ou de Nossa Senhora Aparecida para desenvolverem um bom trabalho com os doentes e seus familiares, com os outros profissionais da equipe de trabalho e para enfrentar situações difíceis. Junqueira (2008), em uma entrevista com oito médicos de diferentes instituições, descreve que estes profissionais recorrem à espiritualidade, ao transcendente e aos rituais religiosos como recurso de enfrentamento na lida cotidiana com a morte e doenças severas. Há também nestes momentos uma postura mais contemplativa diante de um Deus interno, cultivando a religiosidade em seu próprio mundo, sem frequentarem rituais.

Melo Jr. (2012), em uma entrevista com dez médicos intensivistas do Hospital de Emergência e Trauma Senador Humberto Lucena, da cidade de João Pessoa, aponta que a presença da religiosidade/espiritualidade na comunicação profissional feita pelo médico seria de grande relevância para melhorar a qualidade de vida do paciente e a relação com os familiares e a equipe médica.

Camila Freitas (2011), em uma abordagem quantitativa descritiva e exploratória, investiga a dimensão espiritual no trabalho de 98 enfermeiros que atuam em atenção básica na microrregião de Irecê, na Bahia. Houve percepções positivas acerca da espiritualidade no trabalho relacionada com mais comprometimento afetivo (um vínculo emocional com a organização). Mendes (2002) pesquisa a reumanização do trabalho da enfermeira executiva com 
enfoque na contribuição positiva da dimensão espiritual para a sua qualidade de vida pessoal e profissional.

Em um estudo sobre o uso do coping religioso/espiritual em 126 enfermeiras da Unidade de Urgência e Emergência do Hospital das Clínicas de Ribeirão Preto, Jesus (2012) constatou um alto nível de religiosidade sem nenhum impacto negativo na vida profissional e pessoal desses profissionais, sendo necessários novos estudos para analisar o impacto negativo do coping R/E.

\section{A INTEGRAÇÃO DA RELIGIOSIDADE/ESPIRITUALIDADE NA FORMAÇÃO ACADÊMICA E NO TRABALHO DOS PROFISSIONAIS DA SAÚDE}

Apontam-se estudos que demonstram as dificuldades e os desafios da integração da religiosidade/espiritualidade na formação acadêmica e no trabalho dos profissionais da saúde.

Cavalheiro (2010) aplica um questionário biossociodemográfico da Escala de Bem-Estar Espiritual (EBE) e da Subescala de Religiosidade, Espiritualidade e Crenças Pessoais (SRPB-WHOQOL-100) em formandos e calouros de Psicologia de todas as Universidades de Pelotas (RS). Constata que a espiritualidade aparece significativamente menor nos formandos do que nos calouros. Ainda os formandos referem acreditar em Deus e/ou em uma força superior de modo significativamente menor do que os calouros. Identificou-se que os formandos e os calouros de Psicologia se sentem despreparados ou indiferentes para atender à demanda da espiritualidade na clínica psicológica.

A falta de preparo e a indiferença dos formandos e calouros de Psicologia com a religiosidade/espiritualidade como uma dimensão que integra o humano é preocupante, na medida em que a influência dessa dimensão na saúde psíquica, como o bem-estar espiritual/religioso, possivelmente não será contemplada na prática clínica destes futuros profissionais. Neste sentido, sugere-se que desde o início até o final do curso de Psicologia, assuntos em torno da religiosidade/espiritualidade e saúde, como o bem-estar espiritual/religioso, sejam abordados na grade curricular.

Gastaud (2006), por meio de uma escala de bem-estar espiritual, o SelfReporting Questionnaire (SRQ-20), e de informações sociodemográficas, constatou que $84,6 \%$ dos alunos de Psicologia apresentaram espiritualidade negativa, comparados a 68,8\% dos acadêmicos de Medicina. Gastaud ressalta uma preocupação de existir estudantes da área da saúde que se mostrem distantes das questões espirituais/religiosas, levando-se em conta a relação entre espiritualidade/saúde e doença. Ainda, para Gastaud, um dos motivos 
para que alunos de Psicologia se mostrem distantes das questões espirituais/religiosas, está na separação entre ciência e religião ocorrida nos séculos passados. Neste sentido, dentro da grade curricular do curso de Psicologia, é necessário estudar a importância da relação entre a ciência, neste caso, a Psicologia, e a Religião. Por exemplo, Gastaud, em seu estudo, aponta pesquisas da área da saúde sobre o papel da religião em forma de instituição social como organizadora da experiência subjetiva e para a saúde mental.

Tomasso (2011), em um estudo transversal com 30 docentes e 118 discentes de enfermagem da Faculdade de Enfermagem da Universidade Nove de Julho, em São Paulo, constatou que mais de 95\% dos profissionais possuem algum tipo de filiação religiosa; $96 \%$ acreditam que a espiritualidade influencia muito a saúde do paciente e $77 \%$ se sentem à vontade para abordar o assunto no trabalho - mas somente $36 \%$ julgam-se preparados. As principais barreiras em abordar o assunto foram: a falta de tempo devido às atribuições profissionais, a negligência diante da questão da dimensão espiritual/religiosa como parte da grade curricular, o medo de impor as próprias crenças e o medo de ofender os pacientes. Portanto, cabe aos cursos de Enfermagem abordar, dentro de disciplina de cuidado em saúde, uma visão holística, que considere a relação entre religiosidade/espiritualidade e saúde.

Souza (2006), em uma entrevista semiestruturada com dez estudantes do décimo período do curso de graduação em Enfermagem de uma universidade pública em Curitiba/PR, constatou que os enfermeiros perceberam que as necessidades espirituais fazem parte do enfoque no cuidado dos pacientes durante as aulas teórico-práticas, os estágios e o voluntariado. Todavia, sentemse despreparados para prestar um cuidado espiritual devido à falta de aprofundamento na formação acadêmica. De fato, a questão da religiosidade/espiritualidade e saúde, muitas das vezes, faz parte de uma disciplina - por exemplo, a Antropologia Filosófica -, que por ordem do Ministério de Educação e Cultura em 1994, foi inserida na grade curricular de graduação em Enfermagem com objetivo de proporcionar aos futuros profissionais conhecimentos sobre as dimensões do ser humano (SOUZA, 2006, p. 48). Todavia, devido ao apontamento de Souza (2006) sobre o despreparo dos enfermeiros em prestar um cuidado espiritual diante da falta de aprofundamento na formação acadêmica, torna-se necessário aumentar as horas-aulas sobre a questão da religiosidade/espiritualidade e saúde, ou desenvolver, dentro da grade curricular de graduação em Enfermagem, uma disciplina específica sobre a religiosidade/espiritualidade no contexto de cuidado em saúde. 
Espinha (2013), em um estudo exploratório, descritivo, transversal e de natureza quantitativa com 146 estudantes do curso de graduação em Enfermagem da Faculdade de Medicina de Marília (FAMEMA), constatou que a religiosidade/espiritualidade está presente na forma de os profissionais da saúde e os pacientes lidarem com os problemas da vida e de saúde. No entanto, pouco se aborda a respeito da religiosidade/espiritualidade no contexto do cuidado em saúde devido à falta de conhecimento e formação sobre tal questão.

Cortez (2009), em estudo descritivo e exploratório com abordagem qualitativa com 52 acadêmicos de enfermagem do $8^{\circ}$ período do Centro Universitário Plínio Leite, em Niterói (RJ), constatou que a religiosidade/espiritualidade está mais presente nos momentos práticos de ensino do que nos teóricos, o que se reflete negativamente na integralidade do cuidado. Os enfermeiros se sentem despreparados para lidar com a dimensão espiritual e religiosa dos pacientes. Portanto, é necessário aumentar o ensino teórico com foco na religiosidade/espiritualidade na prática de cuidado entre os enfermeiros. Por exemplo, realizar uma revisão de literatura sobre a religiosidade/espiritualidade e o cuidado em enfermagem como uma tarefa avaliativa, integrar na linha de pesquisa de trabalhos de conclusão de curso temas sobre religiosidade/espiritualidade e saúde, dentre outros.

Peixoto (2000) descreve a importância da dimensão religiosa cristã na educação em Enfermagem para um cuidado humanizado. Ele aponta que os docentes da área de Enfermagem testificam que pouco se aborda acerca desta dimensão na assistência aos pacientes. Neste sentido, a abordagem dos valores cristãos dentro da formação dos enfermeiros, como o amor ao próximo (Lucas 10:27), uma qualidade humana que é expressa no cuidado fraternal, pode contribuir para prática de cuidado humanizado em saúde.

Para André Dal-Farra e César Geremia (2010), existem algumas formas de integrar a espiritualidade na formação de profissionais da saúde, como, por exemplo, oferecer cursos de extensão e estágios que sejam utilizados como atividades complementares, com uma abordagem na transversalidade, na qual os componentes curriculares tratem das práticas educativas com atenção aos aspectos relativos à espiritualidade e à sua relação com a saúde. Dentro deste contexto, André Dal-Farra e César Geremia apontam instituições de ensino com cursos de Medicina no Brasil que integram a espiritualidade na grade curricular: a Universidade Federal do Ceará oferece em sua matriz curricular uma disciplina optativa no curso de Medicina denominada "Medicina e Espiritualidade"; a Faculdade de Medicina do Triângulo Mineiro traz "Saúde e 
Espiritualidade"; e a Universidade Federal do Rio Grande do Norte, "Medicina, Saúde e Espiritualidade”.

Ressalta-se que o processo de integrar as disciplinas sobre a religiosidade/espiritualidade nos cursos da área da saúde não pode atrapalhar o calendário acadêmico dos estudantes, visto que, em alguns cursos, como a Medicina, já existe uma sobrecarga de atividades curriculares. Portanto, o processo de integrar a religiosidade/espiritualidade na formação acadêmica dos profissionais da saúde deve ser flexível e completar as atividades em outras disciplinas, como a Antropologia, seminários sobre a saúde integral ou humanizada e outros.

Para Vasconcelos (2009), a religiosidade/espiritualidade é uma dimensão presente na cultura do Brasil, em que grande parte da população é religiosa. De fato, a religiosidade/espiritualidade influencia a forma de as pessoas pensarem, sentirem e agirem, em diferentes dimensões, entre elas a saúde. Assim, é necessário refletir em nível acadêmico sobre o significado da espiritualidade como instrumento e espaço de relação educativa entre profissionais e usuários dos serviços de saúde.

\section{CONSIDERAÇÕES FINAIS}

Dentro de uma perspectiva teológica, considera-se que há poucos estudos sobre religiosidade/espiritualidade e profissionais da saúde, conforme visto nos resultados: entre os 29 estudos da CAPES e SCIELO, apenas dois deles são da área da Teologia - Heimann (2003) e Silva (2010), ambos da Escola Superior em Teologia em São Leopoldo (RS) - , sendo esta também a única entre as cinco instituições que realizou estudo de cunho teológico. Outras instituições, como a Pontifícia Universidade Católica de São Paulo e a Universidade Metodista de São Paulo, que possuem cursos na área da saúde e da teologia, realizaram um total de três estudos no campo da Ciência da Religião, uma área próxima da Teologia. Portanto, dentre os 29 estudos, somando os dois estudos de Teologia e os três de Ciência da Religião, cinco (17\%) são, de modo geral, de cunho religioso. Considera-se que, mesmo assim, ainda há pouca produção acadêmica sobre religiosidade/espiritualidade e profissionais da saúde dentro das áreas da Teologia e da Ciência da Religião.

Todavia, considera-se que os demais estudos de outras áreas, como da Enfermagem, da Psicologia, da Bioética e da Antropologia, dispõem, em suas discussões e resultados, de um adendo teológico em relação à religiosidade/espiritualidade e profissionais da saúde, como visto na discussão 
sobre a notável valorização da relação entre religiosidade/espiritualidade e saúde, sobre a importância da religiosidade/espiritualidade na vida pessoal e no trabalho da maioria dos profissionais da saúde, e sobre a necessidade de integrar a religiosidade/espiritualidade no cuidado hospitalar e na formação dos profissionais.

Destacam-se a Enfermagem e a Psicologia como as áreas de conhecimento que mais produzem estudos sobre religiosidade/espiritualidade e profissionais da saúde. Esse dado demonstra que: (a) há um grande interesse e reconhecimento da área da saúde nas questões que envolvem a religiosidade/espiritualidade e saúde; (b) há veracidade na importância de estudos que abordem a religiosidade/espiritualidade e profissionais da saúde; (c) há uma falta de interdisciplinaridade nos trabalhos, já que a maioria dos estudos se concentra nas áreas da Enfermagem e da Psicologia, necessitando, assim, de pesquisas em outros campos da saúde, como a Medicina, e da área humana, como a Teologia.

Neste sentido, considera-se, primeiramente, ser preciso aumentar e dar continuidade à produção de estudos da teologia sobre a saúde, especialmente sobre a questão da religiosidade/espiritualidade no cuidado entre os profissionais da saúde. A ideia é a de que esses estudos sejam compostos com uma metodologia de pesquisa mista e interdisciplinar. Percebe-se nos estudos com abordagem quantitativa, que a Enfermagem é uma área bem presente no contexto do cuidado aos pacientes; já a Psicologia contribui com questões relativas ao comportamento humano religioso diante do estado de saúdedoença. Portanto, diante disso, é necessário um estudo da Teologia sobre a saúde que tenha uma abordagem quantitativa e interdisciplinar, dialogando com outras áreas do conhecimento, especialmente, a Enfermagem e a Psicologia, pois estão bem presentes no contexto de cuidado em saúde.

A abordagem interdisciplinar nos estudos sobre religiosidade, espiritualidade e saúde no campo teológico, pode proporcionar uma visão mais ampla e com novos parâmetros não somente diante do tema do estudo presente, mas também para futuros estudos da teologia com foco no cuidado em saúde, tais como coping religioso/espiritual, conflitos espirituais e práticas de cuidado e a religiosidade/espiritualidade como parte de um cuidado mais integral e humanizado (ESPERANDIO, 2014, p. 827-828).

Em um segundo momento, sob uma ótica teológica no contexto de cuidado em saúde entre os 29 estudos, considera-se que: 
a) Para os profissionais da saúde, há uma relação entre a religiosidade/espiritualidade e a saúde dos pacientes, tendo isso um impacto mais positivo do que negativo no tratamento médico. Esta percepção dos profissionais sobre a influência positiva da religiosidade/espiritualidade na saúde pode, por exemplo, estar associada ao fato de a maioria dos profissionais constatarem um melhor enfretamento ao sofrimento de pacientes que recorrem à sua religiosidade/espiritualidade. Neste contexto, a Teologia enquanto uma ciência que busca estudar questões que se relacionam com as dimensões da religiosidade/espiritualidade pode verificar a contribuição de tais dimensões no contexto de cuidado em saúde, como por exemplo, significar questões centrais entre o sofrimento e o paciente, tais como, de onde procede e para que serve, no intento de proporcionar ao paciente dignidade e seguridade.

Ainda, a percepção dos profissionais da saúde sobre a influência positiva da religiosidade/espiritualidade na saúde pode estar associada à forma pessoal dos profissionais enxergarem a religiosidade/espiritualidade. Sobre isso, os profissionais demostram desenvolver dentro do contexto em saúde uma espiritualidade expressa em práticas de religiosidade, tais como: orações, louvores e meditações. Dentro da conjectura teológica, símbolos litúrgicos e religiosos, como a oração, a imposição de mãos, a bênção, a absolvição, a eucaristia e a unção com óleo, são importantíssimos na perspectiva de salvação, entendidos como um processo contínuo de cura integral do ser humano, ou seja, salvação da alma e do corpo. Nesse sentido, dimensões litúrgicas teológicas como orações, louvores e meditações podem contribuir para o cuidado integral em saúde em que o ser humano é visto pluridimensionalmente, corpo e alma. Nesse processo, os símbolos litúrgicos e religiosos ajudam a celebrar, cultivar e significar ciclos importantes da vida, como por exemplo, o nascimento, sentido e propósito da vida, o sofrimento e o luto.

b) Sobre a integração da religiosidade/espiritualidade no cuidado aos pacientes, observou-se que os profissionais demonstra integrar a religiosidade/espiritualidade no cuidado em saúde, atribuindo ao capelão/pastoralista a responsabilidade do cuidado espiritual/religioso. Nisso, evidencia-se, uma necessidade dos profissionais da saúde participarem do cuidado espiritual/religioso dos pacientes. Neste processo, a teologia pode contribuir com reflexões sobre a influência 
terapêutica das virtudes da religiosidade/espiritualidade para um melhor cuidado em saúde, como por exemplo, temas de Teologia em Psicologia, entre eles, a Psicologia Pastoral pode auxiliar a terapia, a recuperação de pacientes com doenças severas, tais como: o câncer, uma doença que causa impactos biopsicossociais e espirituais nos pacientes. Demandando assim, uma prática de cuidado que vise às questões médicas, psicológicas e teológicas.

Além disto, a Psicologia Pastoral no contexto de cuidado em saúde pode promover um cuidado religioso/espiritual aos próprios profissionais da saúde, ocupando uma função terapêutica, como: conforto em meio à morte e ao sofrimento dos pacientes na incapacidade médica de curá-los, dignidade e valorização pessoal como um aspecto de desenvolvimento e prática profissional, e equilíbrio emocional em meios aos conflitos vivenciados no trabalho.

Outra maneira de promover cuidado psicológico e espiritual é a Terapia da Gestalt, uma abordagem psicológica incluindo dimensões espiritual e religiosa. Pinto (2007) atestou a funcionalidade da Gestalt na sua prática clínica com Clérigos Católicos. Como exemplo, pode-se aplicar no cuidado aos profissionais da saúde religiosos ou pastoralistas/capelães.

c) Entre os desafios e dificuldades dos profissionais da saúde para integrar a religiosidade/espiritualidade no cuidado aos pacientes, a falta de formação e conhecimento acadêmico sobre a questão religiosa/espiritual aparecem como as causas principais. Constatou-se que a formação dos profissionais visa mais o lado científico e biomédico, e pouco se estuda a respeito da influência das dimensões humanas na saúde, entre elas a espiritual e religiosa. Portanto, é necessário inserir disciplinas de cunho teológico que visam contribuir para o contexto de cuidado em saúde, como por exemplo: saúde, bem-estar e espiritualidade, ou, o impacto das crenças religiosas no estado de saúde-doença, e outras. Constatou-se também que os cursos da área da saúde que já possuem disciplinas sobre religiosidade/espiritualidade e saúde precisam aumentar a carga horária, a fim de preparar melhor os profissionais sobre questões religiosas e espirituais na prática do cuidado em saúde. Além disto, é necessário desenvolver mais estratégias educacionais para a integração religiosidade/espiritualidade no contexto de saúde, tais como, estágios e programas de treinamentos e capacitação dos profissionais da saúde. Neste contexto, o capelão/pastoralista, um profissional do campo da 
saúde e também da Teologia e/ou Religião pode ocupar uma função de capacitador, oferecendo aos profissionais da saúde treinamento e conhecimento sobre a abordagem da religiosidade/espiritualidade no cuidado aos pacientes. Também, profissionais da saúde e pacientes, familiares, e comunidade religiosa podem criar grupos, fóruns de discussões que envolvam dimensões teológicas e de cuidado em saúde, como por exemplo, a religião e a prevenção de doenças.

d) Diante do acima exposto, em síntese, a Teologia pode contribuir com reflexões tanto do ponto de vista teórico, como, na formação acadêmica dos profissionais da saúde quanto também de implicações práticas que ajudem na promoção de um cuidado mais integral e humanizado, por exemplo, ajudando o campo da saúde na descoberta pessoal de transcendência do estado de saúde-doença do indivíduo, onde a religiosidade/espiritualidade traz um sentido de vida e conforto em meio ao sofrimento. Além disto, a teologia pode contribuir para os próprios os profissionais da saúde em sua relação com os pacientes e familiares, e em meios aos conflitos vivenciados no trabalho.

e) Por fim, a reflexão teológica no contexto do cuidado em saúde remete à natureza da fé cristã: "estive enfermo, e vocês cuidaram de mim" (Mateus 25:36). Além disto, na natureza da fé cristã a pessoa encontra "vida em abundância” (João 10:10), como sentido de vida e dignidade humana mesmo em uma situação de sofrimento, questões que comungam com campo da saúde na busca de um cuidado humanizado e integral.

\section{REFERÊNCIAS}

\section{ALVES, M. A espiritualidade e os profissionais da saúde em cuidados}

paliativos. Dissertação de Mestrado em Cuidados Paliativos. Lisboa: Faculdade de Medicina de Lisboa, 2011.

ARAÚJO, E. Médicos, médiuns e mediações: um estudo etnográfico sobre médicos-espíritas. Dissertação de Mestrado em Antropologia Social. Curitiba: Universidade Federal do Paraná, 2007.

ARAÚJO, M. O cuidado espiritual: um modelo à luz da análise existencial e da relação de ajuda. Tese de Doutorado em Enfermagem. Fortaleza: Universidade Federal do Ceará, 2011.

BAROLOMEI, M. A fé como fator de resiliência no tratamento do câncer: uma análise do que pensam os profissionais da saúde sobre o papel da espiritualidade na recuperação dos pacientes. Dissertação de Mestrado em Ciências da Religião. São Paulo: Pontifícia Universidade Católica de São Paulo, 2008. 
BÍBLIA DE JERUSALÉM. São Paulo: Paulus, 2002.

BONFIM, N. Um olhar bioético sobre a espiritualidade como fator de saúde para o ser humano em fase terminal. Dissertação de Mestrado em Bioética. São Paulo: Centro Universitário São Camilo, 2010.

CAVALHEIRO, C. Espiritualidade em psicologia: um olhar sobre a formação acadêmica no Rio Grande do Sul. Dissertação de Mestrado em Psicologia. São Leopoldo: Universidade do Vale do Rio dos Sinos, 2010.

CORTEZ, E. Religiosidade e espiritualidade no ensino de enfermagem: contribuição da gestão para a integralidade no cuidado. Tese de Doutorado em Enfermagem. Rio de Janeiro: Universidade Federal do Rio de Janeiro, 2009.

COURAS, R. N. A; KLÜPPEL, B. L. P. . As Cirurgias Espirituais como Catalisadores de Cura - relato de um caso. Religare (UFPB), v. 6, p. 53-66, 2009.

DAL-FARRA, R. A.; GEREMIA, C. "Educação em saúde e espiritualidade: proposições metodológicas”. Rev. bras. educ. med., Rio de Janeiro, v. 34, n. 4, 2010. Disponível em: <http://www.scielo.br/scielo.php?script=sci_arttext\&pid=So10055022010000 400015\&lng=pt\&nrm=iso $>$. Acesso em: 16 dez. 2013.

DERRIDA, Jacques; VATTIMO, Gianni (orgs.). A religião: o seminário de Capri. São Paulo: Estação Liberdade, 2000.

ESPERANDIO, M. R. G. Prayer and Health. A Portuguese Literature Review. Rev. Pistis Prax., Teol. Pastor., Curitiba, v. 6, n. 1, p. 51-66, jan./abr. 2014.

ESPERANDIO, M.; LADD, K. L. Oração e saúde: questões para a Teologia e para a Psicologia da Religião. Horizonte Revista de Estudos de Teologia e Ciências da Religião, v. 11, p. 627-656, 2013.

ESPERANDIO, M. Teologia e a pesquisa sobre espiritualidade e saúde: um estudo piloto entre profissionais da saúde e pastoralistas. Horizonte Revista de Estudos de Teologia e Ciências da Religião, v. 12, n. 35, p. 805-832, jul./set. 2014b.

ESPÍNDULA, J. O significado da religiosidade para pacientes com câncer e para profissionais da saúde. Tese de Doutorado em Enfermagem Psiquiátrica. Ribeirão Preto: Universidade de São Paulo de Ribeirão Preto, 2009.

ESPINHA, Daniele Corcioli Mendes et al . Opinião dos estudantes de enfermagem sobre saúde, espiritualidade e religiosidade. Rev. Gaúcha Enferm., Porto Alegre, v. 34, n. 4, p. 98-106, Dec. 2013. Disponível em: <http://dx.doi.org/10.1590/S198314472 013000400013>. Acesso em: 22 Maio 2015.

FREITAS, C. Espiritualidade no trabalho como fator de comprometimento organizacional: o caso das enfermeiras da microrregião de Irecê-Bahia. Dissertação de Mestrado em Administração. João Pessoa: Universidade Federal da Paraíba, 2011.

FREITAS, E. O olhar do enfermeiro à luz da espiritualidade e na qualidade de vida do paciente oncológico: uma reflexão bioética. Dissertação de Mestrado em Bioética. São Paulo: Centro Universitário São Camilo, 2012. 
GASTAUD, Marina Bento et al. Bem-estar espiritual e transtornos psiquiátricos menores em estudantes de psicologia: estudo transversal. Rev. Psiquiatr. Rio Grande do Sul, Porto Alegre, v. 28, n. 1, 2006. Disponível em:

<http://www.scielo.br/scielo.php?script=sci_arttext\&pid=S010181082006000100003 \&lng=pt\&nrm=iso > . Acesso em: 16 dez. 2013.

GERONE, Lucas Guilherme Teztlaff de. Um olhar sobre a Religiosidade/Espiritualidade na Prática do Cuidado entre profissionais de saúde e pastoralistas. Dissertação (Mestrado em Teologia) - Escola de Educação e Humanidades. Pontifícia Universidade Católica do Paraná. Curitiba, 2015. Disponível em: <http://www.biblioteca.pucpr.br/tede/tde_busca/arquivo.php?codArquivo= 3116>. [Acesso em 27 dez. 2016.]

GOBATTO, C. Religiosidade e espiritualidade em oncologia: um estudo sobre as concepções de profissionais da saúde. Dissertação de Mestrado em Processos de Desenvolvimento Humano e Saúde. Brasília: Universidade de Brasília, 2012.

HEIMANN, T. Cuidando de cuidadores: acompanhamento a profissionais que assistem pacientes em UTI'S - uma abordagem a partir da psicologia pastoral. Dissertação de Mestrado em Teologia. São Leopoldo: Escola Superior de Teologia, 2003.

Henning, M; Moré, C. Religião e Psicologia: análise de interfaces temáticas. Revista REVER, São Paulo (PUC-SP), p. 84-114, dez. 2009.

JESUS, L. Coping religioso-espiritual em profissionais de enfermagem que atuam em unidade de urgência e emergência. Dissertação de Mestrado em Enfermagem Psiquiátrica. Ribeirão Preto: Universidade de São Paulo de Ribeirão Preto, 2012.

JUNQUEIRA, L. Vivências de médicos oncologistas: um estudo da religiosidade no cuidado existencial em saúde. Dissertação de Mestrado em Psicologia. Ribeirão Preto: Universidade de São Paulo de Ribeirão Preto, 2008.

KOENIG, H. Medicina, religião e saúde: o encontro da ciência e da espiritualidade. Porto Alegre: LMP, 2012.

KLÜPPEL, B. L. P.; SOUSA, M. S.; FIGUEIREDO, C A.. As práticas integrativas e o desfio de um novo paradigma em saúde. Religare (UFPB), v. 2, p. 33-42, 2007.

KLÜPPEL, B. L. P.; SOUSA, M. S. Aproximações entre o Yoga e o Xamanismo estudados por Eliade e a Homeopatia criada por Hahnemann. Religare (UFPB), v. 5, p. 17-28, 2009.

LIMA, M. A plenitude humana e o cuidado integral na perspectiva de Viktor Frankl. Dissertação de Mestrado em Psicologia Clínica. Recife: Universidade Católica de Pernambuco, 2012.

LUZ, M. Origem etimológica do termo. Disponível em: <http://www.epsjv.fiocruz. $\mathrm{br} /$ dicionario/verbetes/sau.html $>$. Acesso em: $1^{\circ}$ de out. 2013. 
MELO JUNIOR, I. M. de. Espera por um milagre: os médicos diante da morte encefálica de pacientes adultos jovens. Dissertação de Mestrado em Ciências das Religiões. João Pessoa: Universidade Federal da Paraíba, 2012.

MENDES, I. et al. A re-humanização do trabalho da enfermeira executiva: um enfoque na dimensão espiritual. Rev. Latino-Am. Enfermagem, v. 10, n. 3, p. 401-407, jun. 2002.

MOREIRA-ALMEIDA A, et al. Envolvimento religioso e fatores sociodemográficos: resultados de um levantamento nacional no Brasil. Revista de Psiquiatria Clínica v. 37, n. 1, 2010. Disponível em: <http://www.scielo.br/scielo.php?pid=So10160832010000100003\&script=sci_arttext>. Acesso em: 29 set. 2013.

PAIVA, Geraldo José de. Religião, enfrentamento e cura: perspectivas psicológicas. Estud. psicol. (Campinas), Campinas, v. 24, n. 1, p. 99-104, março de 2007. Disponível em: <http:// dx.doi.org/10.1590/S0103-166X2007000100011>. Acesso em: 21 nov. 2016.

PANZINI, R. Escala de coping religioso-espiritual (escala CRE). Dissertação de Mestrado em Psicologia. Porto Alegre: Universidade Federal do Rio Grande do Sul, 2004.

PINTO, Ênio Brito. Gestalt-terapia de curta duração para clérigos católicos: elementos para a prática clínica. Tese de Doutorado em Ciências da Religião. São Paulo: Pontifícia Universidade Católica de São Paulo, 2007.

PIXOTO, L. Dimensão religiosa cristã na educação em enfermagem. Dissertação de Mestrado em Ciências da Religião. São Paulo: Universidade Metodista de São Paulo, 2000.

PEREIRA, V. N. A; KLÜPPEL, B. L. P. A Cura pela fé. Um diálogo entre Ciência e Religião. Caminhos. Goiânia, v. 12, n. 1, p. 93-104, jan./jun. 2014.

PERES, M. F. P. et al. A importância da integração da espiritualidade e da religiosidade no manejo da dor e dos cuidados paliativos. Revista Psiquiatra Clínica, São Paulo, v. 34, 2007. Disponível em <http://www.scielo.br/scielo.php?script=sci_arttext\&pid= So101-60832007000700011\&lng=pt\&nrm=iso $>$. Acesso em: 16 dez. 2013.

PUCHALSKI, C. M. Espiritualidade e medicina: os currículos na educação médica. Journal of Education Câncer: O Jornal Oficial da Associação Americana para a Educação do Câncer, 21 (1), pp. 14-18, 2006.

REZENDE, E. O espiritismo e a arte médica. Tese de Doutorado em Ciências Sociais. São Paulo: Pontifícia Universidade Católica de São Paulo, 2012.

SCLIAR, M. Histórico do conceito de saúde. PHYSIS: Rev. Saúde Coletiva, Rio de Janeiro, n. 17, v. 1, pp. 29-41, 2007.

SILVA, A. A capelania hospitalar: uma contribuição na recuperação do enfermo oncológico. Dissertação de Mestrado em Teologia. São Leopoldo: Escola Superior de Teologia, 2010. 
SILVA, M. Capelania Hospitalar como Práxis libertadora junto às pessoas com HIV/AIDS. 2007, 123f. Dissertação (Mestrado em Ciências da Religião) Universidade Metodista de São Paulo. São Bernardo do Campo, 2007.

SIMOES, A. S.; KLÜPPEL, B. L. P.; SOUSA, S.. Bem-Estar Espiritual e Síndrome de Burnout em Psicólogos de Hospitais Públicos em João Pessoa. Logos \& Existência, v. 1, p. 192-202, 2012.

SOUZA, J. A dimensão espiritual no cuidado de enfermagem: vivência do estudante de graduação. Dissertação de Mestrado em Enfermagem. Curitiba: Universidade Federal do Paraná, 2006.

SOUZA, W. A espiritualidade como fonte sistêmica na Bioética. Rev. Pistis Prax., Teol. Pastor., Curitiba, v. 5, n. 1, pp. 91-121, jan./jun. 2013.

TEIXEIRA, J. O significado da intervenção médica e da fé religiosa para o paciente idoso com câncer e a percepção dos profissionais da saúde. Tese de Doutorado em Saúde Pública. São Paulo: Universidade de São Paulo, 2003.

TOMASSO, C. de S.; BELTRAME, I. L.; LUCCHETTI, G. Conhecimento e atitudes de professores de enfermagem e estudantes sobre a interface entre religiosidade, espiritualidade e saúde. Rev. Latino-Am. Enfermagem, Ribeirão Preto, v. 19, n. 5, out. 2011. Disponível em: <http://www.scielo.br/scielo.php?script=sci_arttext\&pid=S 0104-11692011000500019\&lng=en\&nrm=iso >. Acesso em: 16 dez. 2013.

VASCONCELOS, Eymard Mourão. Espiritualidade na saúde em educação popular. Cad. CEDE, Campinas, v. 29, n. 79, 2009. Disponível em: $<$ http://www.scielo.br/scielo.php?script=sci_arttext\&pid=S0101-3262200900030000 $3 \& \operatorname{lng}=$ en\&nrm $=$ iso $>$. Acesso em: 16 dez. 2013. 